\title{
Dinuclear Silver(I) Nitrate Complexes with Bridging Bisphosphinomethanes: Argentophilicity and Luminescence
}

\author{
Kristina F. Baranova ${ }^{1,2}$, Aleksei A. Titov ${ }^{1, *(\mathbb{C})}$, Oleg A. Filippov ${ }^{1,3}{ }^{\circledR}$, Alexander F. Smol'yakov ${ }^{1}$, \\ Alexey A. Averin 4 and Elena S. Shubina $1, * \mathbb{D}$ \\ 1 A. N. Nesmeyanov Institute of Organoelement Compounds, Russian Academy of Sciences, Vavilov Str., 28, \\ 119991 Moscow, Russia; krisbar99@gmail.com (K.F.B.); h-bond@ineos.ac.ru (O.A.F.); \\ rengenhik@gmail.com (A.F.S.) \\ 2 Faculty of Chemistry, Lomonosov Moscow State University, 1-3 Leninskie Gory, 119991 Moscow, Russia \\ 3 Shemyakin-Ovchinnikov Institute of Bioorganic Chemistry, Russian Academy of Sciences, \\ Miklukho-Maklaya St., 16/10, 117997 Moscow, Russia \\ 4 A. N. Frumkin Institute of Physical Chemistry and Electrochemistry, Russian Academy of Sciences, \\ Leninsky prosp. 31/4, 199071 Moscow, Russia; alx.av@yandex.ru \\ * Correspondence: tit@ineos.ac.ru (A.A.T.); shu@ineos.ac.ru (E.S.S.); Tel.: +7-499-135-1871 (E.S.S.)
}

Received: 3 July 2020; Accepted: 25 September 2020; Published: 29 September 2020

\begin{abstract}
Two silver nitrate complexes with bisphosphines were obtained and characterized: $[\mathrm{Ag}(\mathrm{dcypm})]_{2}\left(\mathrm{NO}_{3}\right)_{2}\left(\mathbf{1} ; \mathrm{dcypm}=\right.$ bis (dicyclohexylphosphino)methane) and $[\mathrm{Ag}(\mathrm{dppm})]_{2}\left(\mathrm{Me}_{2} \mathrm{Pz}^{\mathrm{H}}\right)_{\mathrm{n}}$ $\left(\mathrm{NO}_{3}\right)_{2}\left(\mathrm{n}=1, \mathbf{2} \mathbf{a} ; \mathrm{n}=2, \mathbf{2} \mathbf{b} ; \mathrm{dppm}=\right.$ bis(diphenylphosphino)methane, $\mathrm{Me}_{2} \mathrm{Pz}^{\mathrm{H}}=3,5$-dimethylpyrazole). The steric repulsions of bulky cyclohexyl substituents prevent additional ligand coordination to the silver atoms in 1. Compounds obtained feature the bimetallic eight-member cyclic core $[\mathrm{AgPCP}]_{2}$. The intramolecular argenthophilic interaction $(\mathrm{d}(\mathrm{Ag} \cdots \mathrm{Ag})=2.981 \AA$ ) was observed in complex 1 . In contrast, the coordination of pyrazole led to the elongation of Ag...Ag distance to 3.218(1) $\AA$ in $2 \mathbf{a}$ and $3.520 \AA$ in $\mathbf{2 b}$. Complexes 1 and 2a possess phosphorescence both in the solution and solid state. Time-dependent density-functional theory (TD-DFT) calculations demonstrate the origin of their different emission profile. In the case of $\mathbf{1}$, upon excitation, the electron leaves the Ag-P bonding orbital and locates on the intramolecular Ag...Ag bond (metal-centered character). Complex 2a at room temperature exhibits a phosphorescence originating from the ${ }^{3}\left(\mathrm{M}+\mathrm{L}^{\mathrm{P}+\mathrm{N}}\right) \mathrm{L}^{\mathrm{Ph}} \mathrm{CT}$ state. At $77 \mathrm{~K}$, the photoluminescence spectrum of complex 2a shows two bands of two different characters: ${ }^{3}\left(\mathrm{M}+\mathrm{L}^{\mathrm{P}+\mathrm{N}}\right) \mathrm{L}^{\mathrm{Ph}} \mathrm{CT}$ and ${ }^{3} \mathrm{LC}^{\mathrm{Ph}}$ transitions. The contribution of Ag atoms to the excited state in both complexes $\mathbf{2 a}$ and $\mathbf{2 b}$ decreased relative to $\mathbf{1}$ in agreement with the structural changes caused by pyrazole coordination.
\end{abstract}

Keywords: silver phosphine; pyrazole; luminescence; TD-DFT

\section{Introduction}

The non-covalent metal-metal interactions play a significant role in the emission $[1,2]$ or catalytic [3-5] properties of the $\mathrm{d}^{10}$ metal complexes. Dinuclear or trinuclear coinage metal complexes with bridging bis- or trisphosphine ligands represent a unique class of molecules occupying a position between mononuclear complexes and nanoparticles. They have remarkable chemical and physicochemical properties due to the presence of metal-metal bonds of various energy [6]. For example, di- and tetranuclear silver nitrates with bis(diphenylphosphino)methane are known since 1983 [7]. The metal-centered (MC) nature of emission is well known for coinage metal complexes with bridging phosphines. Already in 1989 , Che et al. showed on an example of gold dimer $\left[\mathrm{Au}_{2}(\mathrm{dppm})_{2}\right]^{2+}$ 
that shortened $\mathrm{Au}-\mathrm{Au}$ distances participate in electron transitions [8]. Then, on the example of silver dinuclear complexes with bisphosphines $[\mathrm{Ag}(\mathrm{dcypm})]_{2} \mathrm{X}_{2}\left(\mathrm{X}=\mathrm{PF}_{6}{ }^{-}\right.$, and $\mathrm{CF}_{3} \mathrm{SO}_{3}{ }^{-}$, or $\mathrm{CN}^{-}$; dcypm $=$ bis(dicyclohexylphosphino)methane) $[9,10]$ and $[\mathrm{Ag}(\mathrm{dmb})]_{2} \mathrm{X}_{2}$ complexes $(\mathrm{X}=\mathrm{Cl}, \mathrm{Br}$, I; $\mathrm{dmb}=1,8$-diisocyano- $\rho$-menthane) [11], it has been shown that UV-Vis (Ultraviolet-visible) absorption band of complexes to $\mathrm{d}-\mathrm{p}$ transition from intramolecular argentophilic interaction. The metallophilic nature of this band corresponding to the stretching $\mathrm{Ag}-\mathrm{Ag}$ vibration $\left(80 \mathrm{~cm}^{-1}\right)$ was proven by Raman spectroscopy with excitation at the UV maximum [9]. The same behavior has also been observed for metallothioneins $[11,12]$ and nanoclusters $[13,14]$. The interaction between two coinage metal ions has been investigated by spectral as well as computational methods $[15,16]$. Recently, using the example of $\mathrm{Au} / \mathrm{Ag}$ di- and trinuclear complexes with diphosphanyl NHC ligands, this phenomenon was explained experimentally and theoretically [17].

Surprisingly, despite the wide structural diversity of coinage metals and bisphosphine complexes, there is practically no information about silver(I) nitrate complexes. Herein, we present the synthesis, structures, photophysical properties of dinuclear silver(I) bisphosphines $[\mathrm{Ag}(\mathrm{dcypm})]_{2}\left(\mathrm{NO}_{3}\right)_{2}(\mathbf{1})$ $\left(\right.$ dcypm $=$ bis(dicyclohexylphosphino)methane) and $[\mathrm{Ag}(\mathrm{dppm})]_{2}\left(\mathrm{Me}_{2} \mathrm{Pz}^{\mathrm{H}}\right)_{\mathrm{n}}\left(\mathrm{NO}_{3}\right)_{2}(\mathrm{n}=1, \mathbf{2 a} ; \mathrm{n}=2$, 2b) $($ dppm $=$ diphenylphosphino)methane) with 3,5-dimethylpyrazole (Scheme 1). The influence of $\mathrm{Ag} \cdots \mathrm{Ag}$ distances or the ligand at silver atoms on the emission properties will be discussed involving the theoretical interpretation.

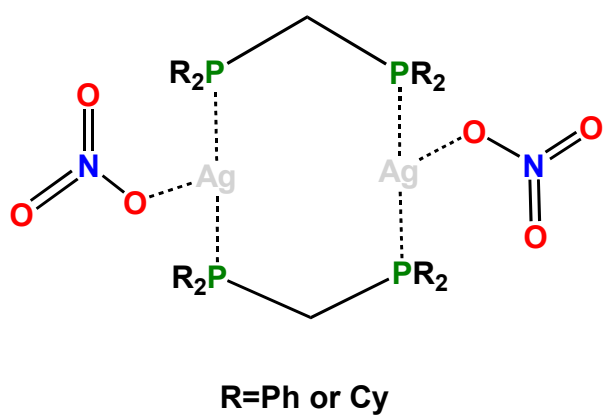

Scheme 1. Representation of central $[\mathrm{MPCP}]_{2}$ core for the complexes studied $(\mathrm{R}=\mathrm{Cy}(\mathbf{1}), \mathrm{Ph}(\mathbf{2}))$.

\section{Materials and Methods}

${ }^{1} \mathrm{H}$ and ${ }^{31} \mathrm{P}\left\{{ }^{1} \mathrm{H}\right\}$ nuclear magnetic resonance (NMR) measurements were carried out on a Bruker Avance 400 spectrometer. Infrared (IR) spectra were collected on a Shimadzu IR Prestige-21 FT-IR (Fourier-transform infrared spectroscopy) spectrometer using $\mathrm{KBr}$ pellets. The photoluminescence spectra and lifetime measurements of the phosphors were recorded at $77 \mathrm{~K}$ and $298 \mathrm{~K}$ on a Fluorolog-3 spectrofluorometer system (HORIBA Jobin-Yvon, the excitation source was a $450 \mathrm{~W}$ xenon lamp with Czerny-Turner double monochromators, and the registration channels were a R928 photomultiplier, while a $150 \mathrm{~W}$ pulsed xenon lamp was used for lifetime measurements). The powders for these measurements were packed in quartz capillaries. The phosphorescence quenching curves were analyzed using the FluoroEssence ${ }^{\mathrm{TM}}$ software for calculation of the phosphorescence lifetime values. The UV-Vis spectra were measured on a Cary50 spectrometer.

X-ray diffraction study. Single-crystal X-ray diffraction experiments for complexes $\mathbf{1}, \mathbf{2 a}$, and $\mathbf{2 a} \mathbf{2} \mathbf{2 b}$ were carried out with a Bruker SMART APEX II diffractometer. The structures were solved by the direct method and refined in anisotropic approximation for non-hydrogen atoms. Hydrogen atoms of methyl, methylene, and aromatic fragments were calculated according to those idealized geometries and refined with constraints applied to $\mathrm{C}-\mathrm{H}$ and $\mathrm{N}-\mathrm{H}$ bond lengths and equivalent displacement parameters $\left(\mathrm{U}_{\mathrm{eq}}(\mathrm{H})=1.2 \mathrm{U}_{\mathrm{eq}}(\mathrm{X})\right.$, where $\mathrm{X}$ is the central atom of the $\mathrm{XH}_{2}$ group; and $\mathrm{U}_{\mathrm{eq}}(\mathrm{H})=1.5 \mathrm{U}_{\mathrm{eq}}(\mathrm{Y})$, $\mathrm{Y}$-central atom of $\mathrm{YH}_{3}$ group). All structures were solved with the ShelXT program [18] and refined with the ShelXL program [19]. Molecular graphics were drawn using the OLEX2 program [20]. The cyclohexyl fragment in complex $\mathbf{1}, \mathrm{Me}_{2} \mathrm{Pz}^{\mathrm{H}}$ ligand in complex $\mathbf{2 a}$, and in the second molecule 
in co-crystal $\mathbf{2} \mathbf{a} / \mathbf{2} \mathbf{b}$ were disordered, and the occupancy of positions of disordered levels was 0.5 . Nitrate anions in the second molecule (2a) in co-crystal $\mathbf{2 a} \mathbf{a} \mathbf{2} \mathbf{b}$ were disordered, and the occupancy of positions of disordered levels were 0.3 and 0.7. CCDC 2013947, 2013948, and 2033764 contained the supplementary crystallographic data for complexes $\mathbf{1}, \mathbf{2} \mathbf{a}$, and $\mathbf{2} \mathbf{a} / \mathbf{2} \mathbf{b}$. These data can be obtained free of charge from the Cambridge Crystallographic Data Center via https://www.ccdc.cam.ac.uk/structures. Crystal data and structure refinement parameters are presented in Table 1.

Table 1. Crystallographic data for complexes $\mathbf{1}, \mathbf{2 a}$, and $\mathbf{2 a / 2} \mathbf{b}$.

\begin{tabular}{|c|c|c|c|}
\hline & 1 & $2 a$ & $2 a / 2 b$ \\
\hline $\begin{array}{l}\text { Empirical Formula } \\
\text { Formula weight }\end{array}$ & $\begin{array}{c}\mathrm{C}_{25} \mathrm{H}_{46} \mathrm{AgNO}_{3} \mathrm{P}_{2} \\
578.44\end{array}$ & $\begin{array}{c}\mathrm{C}_{55} \mathrm{H}_{53} \mathrm{Ag}_{2} \mathrm{~N}_{4} \mathrm{O}_{6} \mathrm{P}_{4} \\
1205.63\end{array}$ & $\begin{array}{c}\mathrm{C}_{117} \mathrm{H}_{116} \mathrm{Ag}_{4} \mathrm{Cl}_{2} \mathrm{~N}_{5} \mathrm{O}_{6} \mathrm{P}_{4} \\
2675.24\end{array}$ \\
\hline Diffractometer & $\begin{array}{l}\text { Bruker SMART APEX } \\
\text { CCD }\end{array}$ & $\begin{array}{l}\text { Bruker SMART APEX } \\
\text { CCD }\end{array}$ & $\begin{array}{c}\text { Bruker SMART APEX } \\
\text { CCD }\end{array}$ \\
\hline Scan mode & $\phi$ and $\omega$ scans & $\phi$ and $\omega$ scans & $\omega$ and $\phi$ scans \\
\hline Anode [Wavelength, Å] & $\begin{array}{c}\text { MoK } \alpha[0.71073] \text { sealed } \\
\text { tube }\end{array}$ & $\begin{array}{c}\text { MoK } \alpha[0.71073] \text { sealed } \\
\text { tube }\end{array}$ & $\begin{array}{c}\text { MoK } \alpha[0.71073] \text { sealed } \\
\text { tube }\end{array}$ \\
\hline $\begin{array}{c}\text { Crystal Dimensions, mm } \\
\text { Crystal color }\end{array}$ & $\begin{array}{c}0.1 \times 0.15 \times 0.36 \\
\text { colorless }\end{array}$ & $\begin{array}{c}0.08 \times 0.11 \times 0.15 \\
\text { colorless }\end{array}$ & $\begin{array}{c}0.08 \times 0.12 \times 0.44 \\
\text { colorless }\end{array}$ \\
\hline Crystal system & tetragonal & monoclinic & triclinic \\
\hline $\mathrm{a}, \AA$ & $29.8637(11)$ & $10.940(2)$ & 10.9934(13) \\
\hline $\mathrm{b}, \AA$ & $29.8637(11)$ & $19.805(4)$ & $11.9540(14)$ \\
\hline$c, \AA$ & $12.6441(5)$ & $11.719(2)$ & $22.858(3)$ \\
\hline$\alpha, \operatorname{deg}$ & 90 & 90 & $77.727(2)$ \\
\hline$\beta, \operatorname{deg}$ & 90 & $91.087(4)$ & $82.796(2)$ \\
\hline$\gamma, \operatorname{deg}$ & 90 & 90 & $85.688(2)$ \\
\hline Volume, $\AA^{3}$ & 11276.5(9) & $2538.5(9)$ & $2908.5(6)$ \\
\hline Density, $\mathrm{g} \mathrm{cm}^{-3}$ & 1.363 & 1.577 & 1.527 \\
\hline Temperature, $\mathrm{K}$ & 120 & 120 & 120 \\
\hline Tmin/Tmax & $0.7056 / 0.7461$ & $0.6339 / 0.7460$ & $0.6141 / 0.7459$ \\
\hline$\mu, \mathrm{mm}^{-1}$ & 0.853 & 0.953 & 0.930 \\
\hline Space group & $\mathrm{I} 4_{1} / \mathrm{a}$ & $\mathrm{P} 2{ }_{1} / \mathrm{n}$ & P1 \\
\hline $\mathrm{Z}$ & 16 & 2 & 2 \\
\hline $\mathrm{F}(000)$ & 4864 & 1226 & 1360 \\
\hline Reflections collected & 54587 & 23611 & 37353 \\
\hline Independent reflections & 5546 & 4995 & 16342 \\
\hline Reflections $(\mathrm{I}>2 \sigma(\mathrm{I}))$ & 4576 & 3545 & 9421 \\
\hline Parameters & 234 & 308 & 740 \\
\hline $\mathrm{R}_{\text {int }}$ & 0.0350 & 0.1053 & 0.0860 \\
\hline $2 \theta \min -2 \theta \max$ & $2.728-51.998$ & $4.040-52.000$ & $3.670-59.410$ \\
\hline $\mathrm{wR}_{2}$ (all reflections) & 0.2032 & 0.1571 & 0.1221 \\
\hline $\mathrm{R}_{1}(\mathrm{I}>\sigma(\mathrm{I}))$ & 0.0717 & 0.0866 & 0.0561 \\
\hline GOF & 1.027 & 1.220 & 0.972 \\
\hline$\rho_{\min } / \rho_{\max }, \mathrm{e} \AA^{-3}$ & $-1.042 / 1.733$ & $-1.338 / 0.927$ & $-1.011 / 1.385$ \\
\hline
\end{tabular}

Computational details. Full geometry optimizations of complexes 1 and $\mathbf{2}$ were performed using the PBE0 functional [21] and SVP (split valence polarization) basis set [22,23] without any symmetry restrictions using Gaussian09 software [24]. Optimized geometries of $\mathbf{1}, \mathbf{2} \mathbf{a}$, and $\mathbf{2 b}$ reasonably reproduced the X-ray geometry (Figure S14 in the Supplementary Materials). The equilibrium geometry for $\mathbf{1}$ and $\mathbf{2 b}$ had a $C_{i}$ symmetry point group (as it was found by $X$-ray analysis), leading to the symmetry forbidden electronic transitions, so only transitions of $A_{u}$ symmetry were analyzed. For complex 2a, the second pyrazole molecule was left, but rotated to be in the $\mathrm{Me}_{2} \mathrm{PzH}$ ligand position of a neighbor complex in the crystal. Herewith, that molecule remained non-bonded by the Ag-N bond, but its presence helps to keep the complex similar to the X-ray characterized one. Vertical singlet and triplet excitations were calculated by TD-DFT on the same level of theory. Analysis of the excited 
states was done with the Multiwfn program [25]. The similarity of the excited states was analyzed by the approach suggested by Chen [26].

$$
s_{H / E}=1-\frac{\sum_{i}\left|a_{i}-b_{i}\right|}{2}
$$

where $a_{i}$ and $b_{i}$ are contributions of the $i$ atom to the hole $\left(s_{H}\right)$ or electron $\left(s_{E}\right)$ in the states $a$ and $b$.

Synthesis. All operations were performed with Schlenk techniques under a dry argon atmosphere. Commercially available solvents and ligands were used without additional purification.

[Ag(dcypm) $]_{2}\left(\mathrm{NO}_{3}\right)_{2}$ (1). Mixture of $\mathrm{AgNO}_{3}(50 \mathrm{mg}, 0.294 \mathrm{mmol})$ and bis(dicyclohexylphosphino) methane $(120 \mathrm{mg}, 0.294 \mathrm{mmol})$ was stirred in $5 \mathrm{~mL}$ of $\mathrm{CH}_{2} \mathrm{Cl}_{2}$ at room temperature for $3 \mathrm{~h}$. A white solid was afforded upon precipitation by $\mathrm{n}$-hexane. The precipitate formed was filtered, washed with $10 \mathrm{~mL}$ of acetone, and dried in vacuum. Yield $91 \%$. NMR $\left(\mathrm{CD}_{2} \mathrm{Cl}_{2}, \mathrm{ppm}\right){ }^{1} \mathrm{H}: \delta=1.19-2.13$ ppm $\left(\mathrm{m}, 88 \mathrm{H}^{\mathrm{Cy}}\right.$ and $\left.4 \mathrm{CH}_{2}\right),{ }^{31} \mathrm{P}\left\{{ }^{1} \mathrm{H}\right\}: \delta=28.8(\mathrm{~m}, 4 \mathrm{P})$. Anal. calcd/found for $\mathrm{C}_{50} \mathrm{H}_{92} \mathrm{Ag}_{2} \mathrm{~N}_{2} \mathrm{O}_{6} \mathrm{P}_{4}$ : C, $51.91 / 52.01 ; \mathrm{H}, 8.02 / 8.08 ; \mathrm{N}, 2.42 / 2.40$.

$[\mathbf{A g}(\mathbf{d p p m})]_{2}\left(\mathrm{Me}_{2} \mathrm{Pz}^{\mathrm{H}}\right)\left(\mathrm{NO}_{3}\right)_{2}(\mathbf{2 a})$. The suspension of $50 \mathrm{mg}$ of $\mathrm{AgNO}_{3}(0.294 \mathrm{mmol})$ and $17.3 \mathrm{mg}$ of 3,5-dimethylpyrazole $(0.180 \mathrm{mmol})$ was stirred in $10 \mathrm{~mL}$ of acetone for the one hour until a slurry precipitate was formed, and then the solution of dppm $(113 \mathrm{mg}, 0.294 \mathrm{mmol})$ in $3 \mathrm{~mL}$ of acetone was added. The reaction mixture was stirred overnight at room temperature. The precipitate formed was filtered off and washed with $10 \mathrm{~mL}$ of $\mathrm{CH}_{2} \mathrm{Cl}_{2}$. The solution obtained was added to $20 \mathrm{~mL}$ of hexane, and the mixture was kept in the refrigerator at ca. $5{ }^{\circ} \mathrm{C}$ for one hour. The precipitate formed was filtered off, washed with hexane, and both solids were combined and dried under reduced pressure. Complex $2 \mathbf{a}$ was obtained by slow crystallization at room temperature from boiling $\mathrm{CH}_{3} \mathrm{CN}$ solution of small portions of these solids. Yield $68 \%$. NMR $\left(\mathrm{CD}_{3} \mathrm{CN}, \mathrm{ppm}\right){ }^{1} \mathrm{H}: \delta=2.07 \mathrm{ppm}\left(\mathrm{s}, 6 \mathrm{H}, \mathrm{Me}^{\mathrm{Pz}}\right)$, $\left.3.71 \mathrm{ppm}\left(\mathrm{m}, 4 \mathrm{H}, \mathrm{CH}_{2}{ }^{\mathrm{dppm}}\right), 5.74 \mathrm{ppm}\left(\mathrm{s}, 1 \mathrm{H}, \mathrm{CH}^{\mathrm{Pz}}\right), 7.20-7.44\left(\mathrm{~m}, 40 \mathrm{H}, \mathrm{Ph}^{\mathrm{dppm}}\right),{ }^{31} \mathrm{P}^{1}{ }^{1} \mathrm{H}\right\}: \delta=7.5$ (m, 4P); IR (KBr, cm $\left.{ }^{-1}\right): v 3201(v N H), 3138,3050,2922,2876(v \mathrm{CH}), 1580$. Anal. calcd/found for $\mathrm{C}_{55} \mathrm{H}_{54} \mathrm{Ag}_{2} \mathrm{~N}_{4} \mathrm{O}_{6} \mathrm{P}_{4}$ : C, 54.75/54.07; $\mathrm{H}, 4.51 / 4.24 ; \mathrm{N}, 4.64 / 4.60$.

\section{Results and Discussion}

\subsection{Synthetic Procedures}

Complex 1 was obtained by the interaction of $\mathrm{AgNO}_{3}$ with bis(dicyclohexylphosphino)methane (dcypm) in dichloromethane (DCM) and subsequent precipitation with hexane. Moreover, the addition of dcypm to the solution of the complex $\left[\mathrm{Ag}\left(\mathrm{Me}_{2} \mathrm{Pz}^{\mathrm{H}}\right)\right] \mathrm{NO}_{3}$ generated in situ only led to complex 1 with high yield. This suggests that the steric effect of bulk cyclohexyl substituents makes impossible the pyrazole coordination to the silver atoms. In contrast, mixing $\mathrm{AgNO}_{3}$ with 3,5-dimethylpyrazole and less sterically demanding bis(diphenylphosphino)methane (dppm) in acetone led to the formation of the precipitate. The elemental analysis and ${ }^{1} \mathrm{H}$ NMR spectrum demonstrated that the composition of the bulk solids corresponded to the complex $\left[\mathrm{Ag}_{2}\left(\mathrm{Me}_{2} \mathrm{PzH}\right)(\mathrm{dppm})\right]_{2}\left(\mathrm{NO}_{3}\right)_{2}(\mathbf{2 b})$ containing two pyrazole molecules per $[\mathrm{Ag}(\mathrm{dppm})]_{2}\left(\mathrm{NO}_{3}\right)_{2}$ moiety (Figures S19 and S20). Unfortunately, reprecipitation or crystallization of this complex at low temperatures led to the partial loss of pyrazole molecules, resulting in a mixture of complexes $[\mathrm{Ag}(\mathrm{dppm})]_{2}\left(\mathrm{Me}_{2} \mathrm{Pz}^{\mathrm{H}}\right)\left(\mathrm{NO}_{3}\right)_{2}(\mathbf{2 a})\left[\mathrm{Ag}_{2}\left(\mathrm{Me}_{2} \mathrm{Pz}^{\mathrm{H}}\right)(\mathrm{dppm})\right]_{2}\left(\mathrm{NO}_{3}\right)_{2}(\mathbf{2} \mathbf{b})$. In a pure form, only complex $2 \mathrm{a}$ could be obtained by slow crystallization from boiling acetonitrile solution at room temperature. It should be noted that the elimination of the second 3,5-dimethylpyrazole molecule was not observed.

\subsection{Crystal Structure of Complexes}

The structures of compounds obtained were proved by single-crystal X-ray diffraction. The crystallographic data and structure refinement details are summarized in Table 1, and the relevant bond distances and angles are collected in Table 2. 
Table 2. Selected geometric parameters (bond lengths in $\AA$, angles in degrees) for complexes $\mathbf{1}$ and $\mathbf{2 a}$.

\begin{tabular}{|c|c|c|c|c|c|c|c|}
\hline \multicolumn{4}{|c|}{ Bonds Lengths } & \multicolumn{4}{|c|}{ Angles } \\
\hline \multicolumn{2}{|c|}{1} & \multicolumn{2}{|c|}{2} & \multicolumn{2}{|c|}{1} & \multicolumn{2}{|l|}{2} \\
\hline Ag1-P1 & $2.396(2)$ & Ag1-P1 & $2.403(2)$ & Ag1-Ag1-P2 & $82.90(4)$ & Ag1-Ag1-P2 & $81.59(5)$ \\
\hline Ag1-O1 & $2.557(9)$ & Ag1-O1 & $2.554(6)$ & Ag1-P1-C1 & $111.1(2)$ & Ag1-O1-N3 & $129.8(5)$ \\
\hline Ag1-Ag1 & $2.9810(7)$ & Ag1-N1 & $2.443(6)$ & Ag1-P1-C2 & $115.5(2)$ & Ag1-N1-N2 & $124.7(5)$ \\
\hline Ag1-P2 & $2.428(2)$ & Ag1-Ag1 & $3.218(1)$ & Ag1-P1-C8 & $113.2(3)$ & P1-Ag1-O1 & $126.5(1)$ \\
\hline P1-C1 & $1.838(8)$ & Ag1-P2 & $2.442(2)$ & Ag1-O1-N1 & $106.9(5)$ & P1-Ag1-N1 & $98.6(2)$ \\
\hline P1-C2 & $1.850(6)$ & P1-C4 & $1.846(8)$ & P1-Ag1-O1 & 119.1(2) & P1-Ag1-Ag1 & $88.90(5)$ \\
\hline P1-C8 & $1.85(1)$ & P1-C17 & $1.801(8)$ & P1-Ag1-Ag1 & $94.21(4)$ & P1-Ag1-P2 & $151.61(8)$ \\
\hline P2-C1 & $1.827(7)$ & P1-C23 & $1.828(8)$ & P1-C1-P2 & 114.4(3) & O1-Ag1-N1 & $84.1(2)$ \\
\hline P2-C17 & $1.84(1)$ & P2-C4 & $1.822(8)$ & P1-Ag1-P2 & $152.22(6)$ & O1-Ag1-Ag1 & $91.5(1)$ \\
\hline P2-C23 & $1.844(6)$ & P2-C5 & $1.827(8)$ & O1-Ag1-Ag1 & $74.4(2)$ & O1-Ag1-P2 & $80.7(1)$ \\
\hline O1-N1 & $1.27(1)$ & P2-C11 & $1.804(8)$ & O1-Ag1-P2 & $86.9(2)$ & N1-Ag1-Ag1 & $172.5(2)$ \\
\hline $\mathrm{O} 2-\mathrm{N} 1$ & $1.244(8)$ & P2-Ag1 & $2.442(2)$ & & & N1-Ag1-P2 & $91.7(2)$ \\
\hline \multirow[t]{8}{*}{ O3-N1 } & $1.12(1)$ & O1-N3 & $1.25(1)$ & & & N2-N1-C1 & $101.8(6)$ \\
\hline & & O2-N3 & $1.24(1)$ & & & & \\
\hline & & O3-N3 & $1.24(1)$ & & & & \\
\hline & & N1-N2 & $1.31(1)$ & & & & \\
\hline & & N1-C1 & $1.50(1)$ & & & & \\
\hline & & N1-C2 & $1.58(1)$ & & & & \\
\hline & & $\mathrm{N} 2-\mathrm{C} 3$ & $1.34(1)$ & & & & \\
\hline & & N2-C2 & $1.02(1)$ & & & & \\
\hline
\end{tabular}

Colorless crystals of complex 1 was obtained by slow evaporation of their DCM/hexane $(v / v=2: 1)$ solutions at ca. $5{ }^{\circ} \mathrm{C}$. Complex 1 features a chair form of the eight-member cyclic $[\mathrm{AgPCP}]_{2}$ core (Figure 1), in which silver atom is coordinated to four atoms (two Pdppm (2.396(2) and 2.429(2) $\AA$ ), $\mathrm{O}^{\text {Nitrate }}(2.558(9) \AA)$ and $\mathrm{Ag}(2.9812(7) \AA)$, forming the distorted triangular pyramidal or tetrahedron environment (Figure 2). The angles $\angle \mathrm{P} 1-\mathrm{Ag} 1-\mathrm{P} 2, \angle \mathrm{P} 1-\mathrm{Ag} 1-\mathrm{O} 1, \angle \mathrm{P} 1-\mathrm{Ag} 1-\mathrm{Ag} 1, \angle \mathrm{O} 1-\mathrm{Ag} 1-\mathrm{Ag} 1$ were $152.22(6)^{\circ}, 119.1(2)^{\circ}, 94.21(4)^{\circ}$, and $74.4(2)^{\circ}$, respectively. There were only several examples of the similar $[\mathrm{Ag}(\mathrm{dcypm})]_{2}{ }^{2+}$ core with $\mathrm{PF}_{6}{ }^{-}, \mathrm{CF}_{3} \mathrm{SO}_{3}{ }^{-}$[9], and $\mathrm{CN}^{-}$[10] counter ions. Observed Ag-Ag bond length (2.9812(7) $\AA$ ) was in the range of shared argentophilic interactions [27-29] being non-significantly longer than that present in the literature (av. $2.93 \AA$ ). The central core $[\mathrm{MPCP}]_{2}$ was similar for dinuclear silver bisphosphines, but additional $\mathrm{k}^{1}$ coordination of the nitrate anion led to a significant distortion of the central cycle. Silver atoms as well as $\mathrm{CH}_{2}$ fragments lie out the $\mathrm{P}_{4}$ plane for 0.557 and $0.607 \AA$, respectively. For example, the same parameters for complex with $\mathrm{CN}^{-}$were 0.415 and $0.575 \AA$ [10]. These structural peculiarities reflect the influence of the nitrate anion on the electronic properties of complexes (vide infra). The Ag-P bond lengths (2.396(2) and 2.429(2) A) were typical for the silver bis-phosphines.

Supramolecular packing of $\mathbf{1}$ was realized via the network of weak $\mathrm{C}^{\mathrm{Cy}}-\mathrm{H} \cdots \mathrm{O}^{\text {Nitrate }}$ interactions of neighboring molecules (2.316 $\AA, \angle \mathrm{O}-\mathrm{H}-\mathrm{C}=156.1^{\circ}$; Figure 2) [30,31].

In contrast, in the case of interaction of the silver nitrate with dppm ligand and 3,5-dimethylpyrazole, complexes of different compositions were observed. As demonstrated above, the interaction led to the formation of the precipitate. Analysis of this solid indicates that it mainly contained one Ag atom per one dppm ligand and one $\mathrm{Me}_{2} \mathrm{Pz}^{\mathrm{H}}$ molecule. However, varying the crystallization conditions allowed for two different types of complexes. The solubility of the solids obtained was very low, and crystallization was performed from significantly diluted solutions (mM concentrations). The most stable one was complex 2a containing one pyrazole molecule, crystals that could be obtained at different temperatures $\left(-10,0\right.$, or $\left.25^{\circ} \mathrm{C}\right)$ and from different solvents $\left(\mathrm{MeOH}, \mathrm{CH}_{3} \mathrm{CN}\right.$, and DCM/hexane mixture). Slow crystallization from the boiling $\mathrm{CH}_{3} \mathrm{CN}$ at room temperature was the best condition for obtaining pure complex $\mathbf{2 a}$. Complex $\mathbf{2} \mathbf{b}$ was obtained only as a co-crystal with $\mathbf{2} \mathbf{a}$, representing two independent molecules with one and two $\mathrm{Me}_{2} \mathrm{Pz}^{\mathrm{H}}$ molecules. This sample was crystallized 
in an NMR tube after a ${ }^{1} \mathrm{H}$ NMR experiment in $\mathrm{CD}_{2} \mathrm{Cl}_{2}$, which eventually showed the $1 / 1$ ratio of $\mathrm{Me}_{2} \mathrm{Pz}^{\mathrm{H}} / \mathrm{dppm}$ in solution. These data demonstrate that crystallization from a diluted solution led to the elimination of one pyrazole from the complex $\left[\mathrm{Ag}(\mathrm{dppm}) \mathrm{Me}_{2} \mathrm{Pz}^{\mathrm{H}}\right]_{2}\left(\mathrm{NO}_{3}\right)_{2}(\mathbf{2 b})$, resulting in $\mathrm{a}$ more stable $[\mathrm{Ag}(\mathrm{dppm})]_{2}\left(\mathrm{Me}_{2} \mathrm{Pz}^{\mathrm{H}}\right)\left(\mathrm{NO}_{3}\right)_{2}(\mathbf{2 a})$ complex.

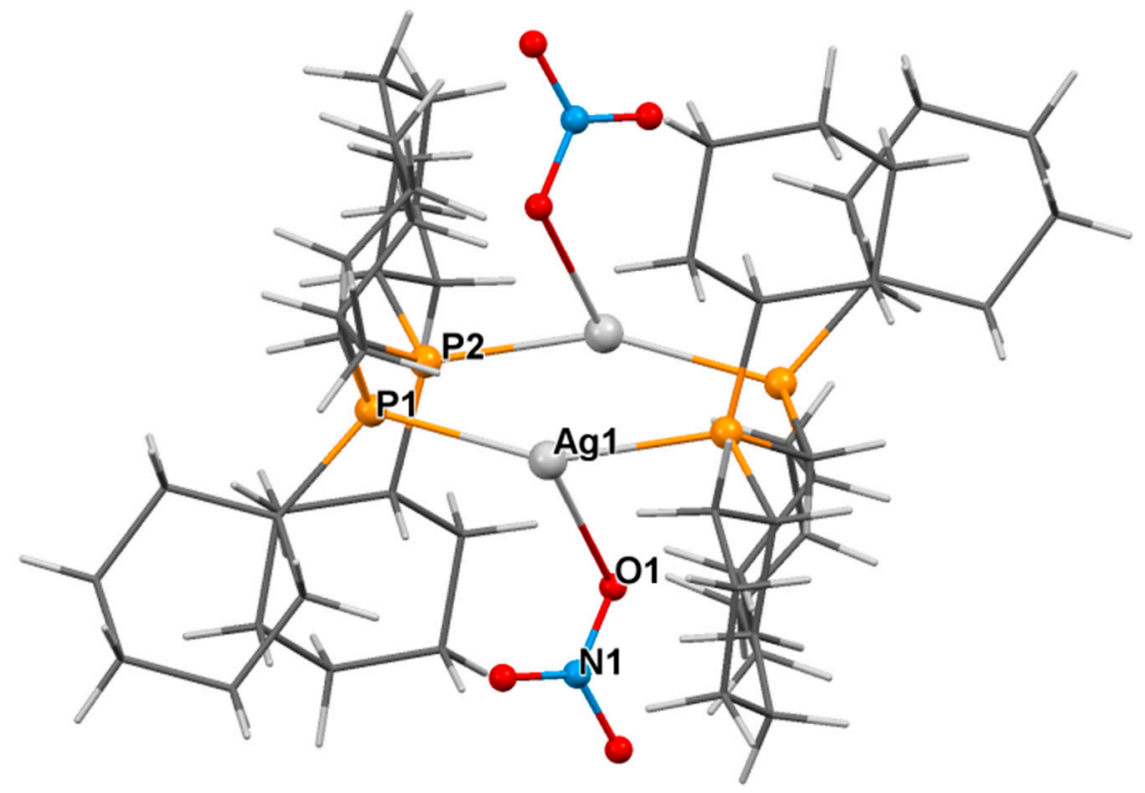

Figure 1. X-ray diffraction (XRD) structure of complex 1 (carbon and hydrogen atoms are shown as sticks).

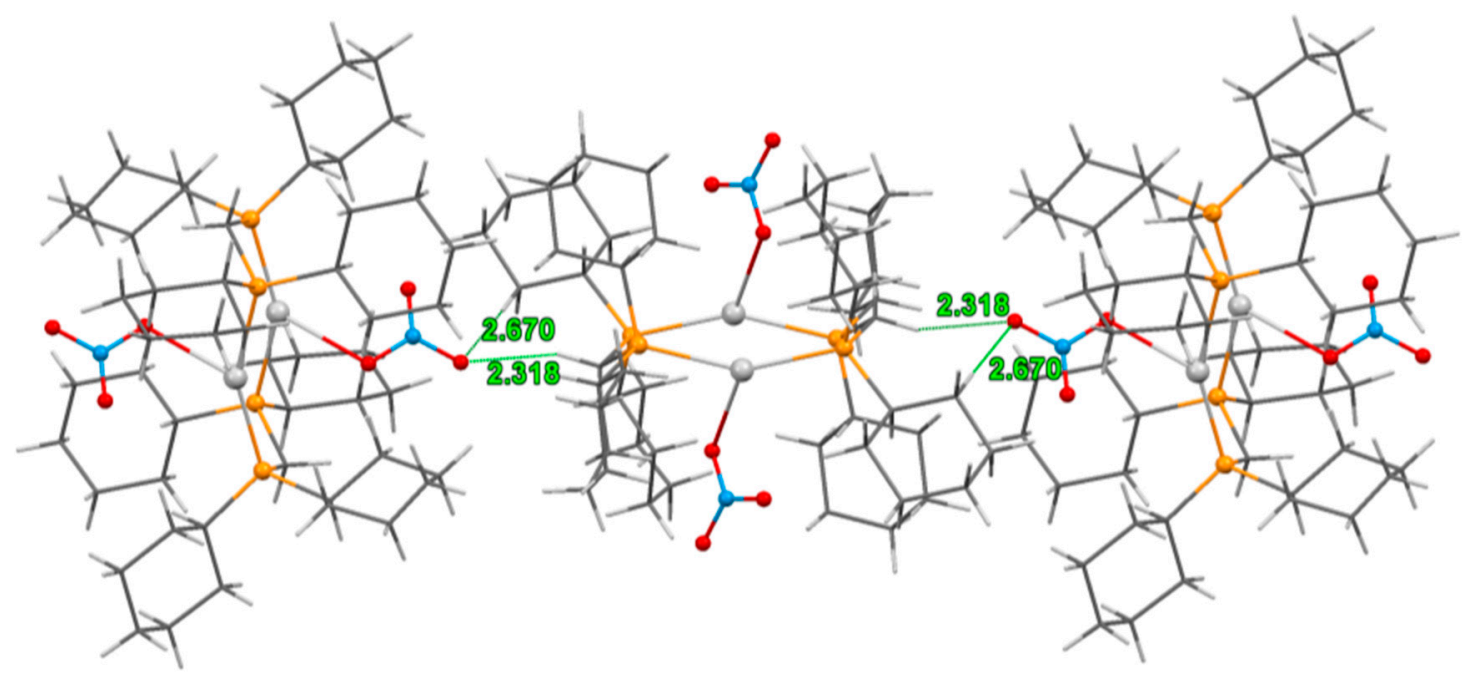

Figure 2. Supramolecular packing of $\mathbf{1}$.

Complex $2 \mathrm{a}$ crystallizes in a chair form of the central $[\mathrm{AgPCP}]_{2}$ cycle (Figure 3 ). There was only one molecule of pyrazole coordinated with one of the silver atoms in the crystal. The complex in the crystal was in the superposition of two possible isomers in which the pyrazole ligand coordinates by nitrogen to both silver atoms (occupation 0.5 ). This behavior leads to the presence of a pseudo inversion center at the center of the $\mathrm{Ag}-\mathrm{Ag}$ distance. Interaction with $\mathrm{Me}_{2} \mathrm{Pz}^{\mathrm{H}}$ ligand led to the pentacoordinate environment distorted trigonal bipyramidal of one silver atom (two Pdppm (2.403(2) and 2.442(2) $\AA$ ), $\mathrm{N}^{\mathrm{Pz}}(2.446(6) \AA), \mathrm{O}^{\text {Nitrate }}(2.554(6) \AA)$, and Ag (3.218(1) $\AA$ ) (Figure 3). The angles P1-Ag1-P2, P1-Ag1-O1, and P1-Ag1-N1 were $151.61(8)^{\circ}, 126.5(1)^{\circ}$, and $98.6(2)^{\circ}$, respectively. The presence of the 3,5-dimethylpyrazole ligand led to the $\kappa^{1}$ coordination of the nitrate to silver atoms in contrast to the 
known $[\mathrm{Ag}(\mathrm{dppm})]_{2}\left(\mathrm{NO}_{3}\right)_{2}$ complex [7,32], which possesses the $k^{2}$ coordination mode of the nitrate anion. Moreover, the coordination of pyrazole led to the elongation of the Ag-Ag distance to $3.218 \AA$, which was significantly longer than that for $[\mathrm{Ag}(\mathrm{dppm})]_{2}\left(\mathrm{NO}_{3}\right)_{2}(3.090-3.110 \AA)[7,32]$. The $\mathrm{Ag}-\mathrm{Ag}$ distance was in the range of closed-shell metallophilic interactions [27]. Silver atoms as well as $\mathrm{CH}_{2}$ fragments, were located on both sides of the $\mathrm{P}_{4}$ plane lying out at 0.594 and $0.720 \AA$, respectively, which determines the chair-configuration of the central $\mathrm{M}_{2} \mathrm{P}_{4}$ core. It should be noted that Tiekink [32] also reported the same configuration for $\left[\mathrm{Ag}(\mathrm{dppm})\left(\mathrm{NO}_{3}\right)\right]_{2}$ with a more distorted central core in contrast to the boat form obtained by Bau [7]. The Ag-P bonds lengths in 2 (2.403(2) and 2.442(2) $\AA$ ) are typical for the silver bis-phosphines complexes. The Ag- $\mathrm{N}^{\mathrm{Pz}}$ bond length (2.446(4) $\AA$ ) is typical for the silver phosphine complexes with donor aromatic nitrogen ligands $[33,34]$. The complex was stabilized via $\mathrm{O}_{1}{ }^{\text {Nitrate }} \ldots \mathrm{H}-\mathrm{N}^{\mathrm{Pz}}$ intramolecular hydrogen bond $\left(1.702 \AA, \angle \mathrm{O}-\mathrm{H}-\mathrm{N}=165.9^{\circ}\right)[30,31]$.

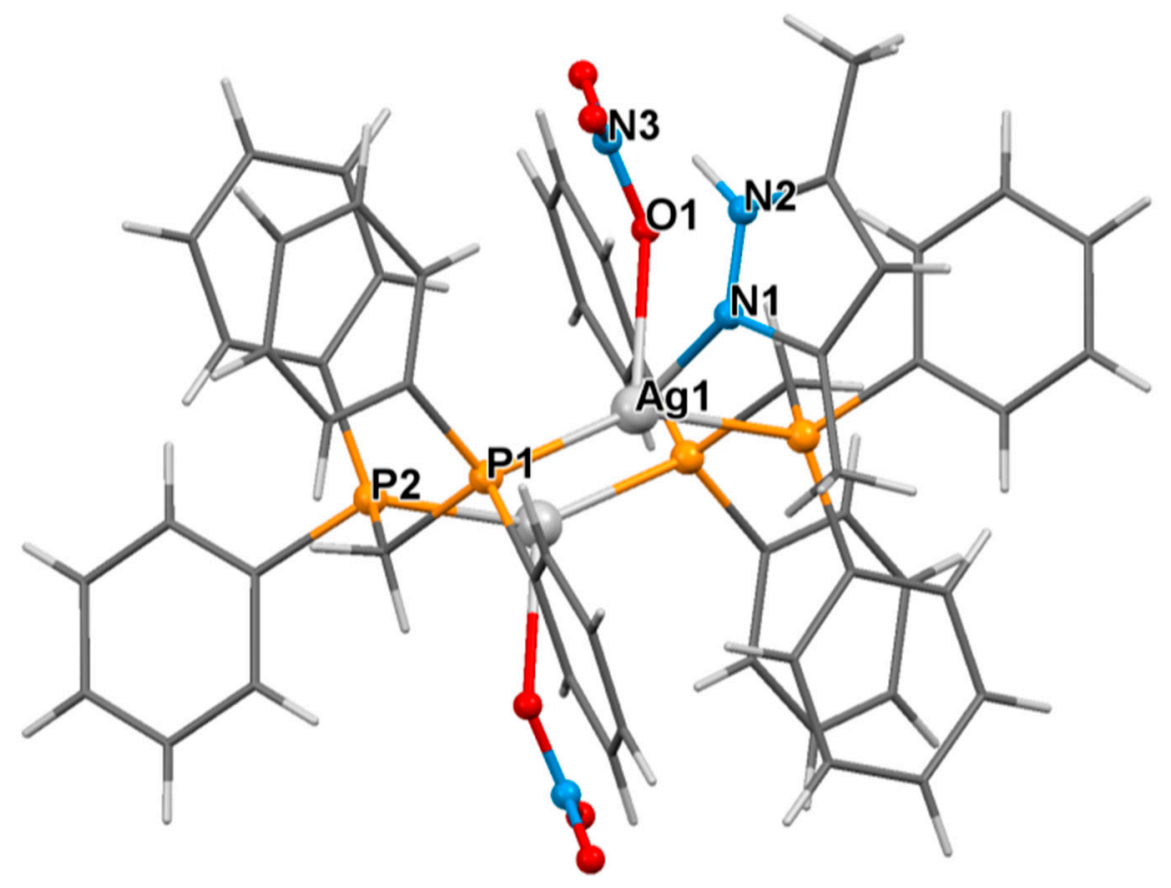

Figure 3. XRD structure of the complex 2 (carbon and hydrogen atoms are shown as sticks).

Complex $\mathbf{2} \mathbf{b}$ was obtained only in the form of a co-crystal of two molecules of general motif $[\mathrm{Ag}(\mathrm{dppm})]_{2}\left(\mathrm{NO}_{3}\right)_{2}$ with one and two pyrazoles, respectively (Figure 4). The part that contained one molecule of pyrazole was generally identical to compound $2 \mathbf{a}$ with non-significant differences in bond lengths and angles. The second part was a dinuclear complex $\mathbf{2 b}$ with two molecules of 3,5-dimethylpyrazole coordinated to both silver atoms. Complex $\mathbf{2} \mathbf{b}$ also crystallized in a chair form of the central $[\mathrm{AgPCP}]_{2}$ cycle. Moreover, there was the inversion center of this fragment in the middle of the Ag-Ag distance. The second pyrazole molecule's coordination led to the significant elongation of the Ag-Ag distance (3.520 $\mathrm{A})$. As a result, the presence of one or two coordinated ligands to the silver atoms in $[\mathrm{Ag}(\mathrm{dppm})]_{2}$ cores led to the elongation of $\mathrm{Ag}-\mathrm{Ag}$ distances and the absence of the shared intramolecular argenthophilic interactions. The Ag-P (2.446(1) and 2.422(1) $\AA$ ) bond lengths were similar to those observed in complexes $\mathbf{1}$ and $\mathbf{2 a}$. The interaction of silver atoms with pyrazoles in $\mathbf{2} \mathbf{b}$ was non-significantly stronger than that for $\mathbf{2} \mathbf{a}$ in accordance with the correlation of the shortened $\mathrm{Ag}-\mathrm{N}^{\mathrm{Pz}}$ bond lengths (2.446(1) $\mathrm{A}$ for $\mathbf{2 a}$ and 2.381(4) $\AA$ for $\mathbf{2 b}$ ). In contrast, the coordination of addition pyrazole led to the significant elongation of the $\mathrm{Ag}-\mathrm{O}^{\text {Nitrate }}$ bonds (2.554(6) $\AA$ for 2a and 2.674 (3) $\AA$ for $\mathbf{2 b}$ ). 


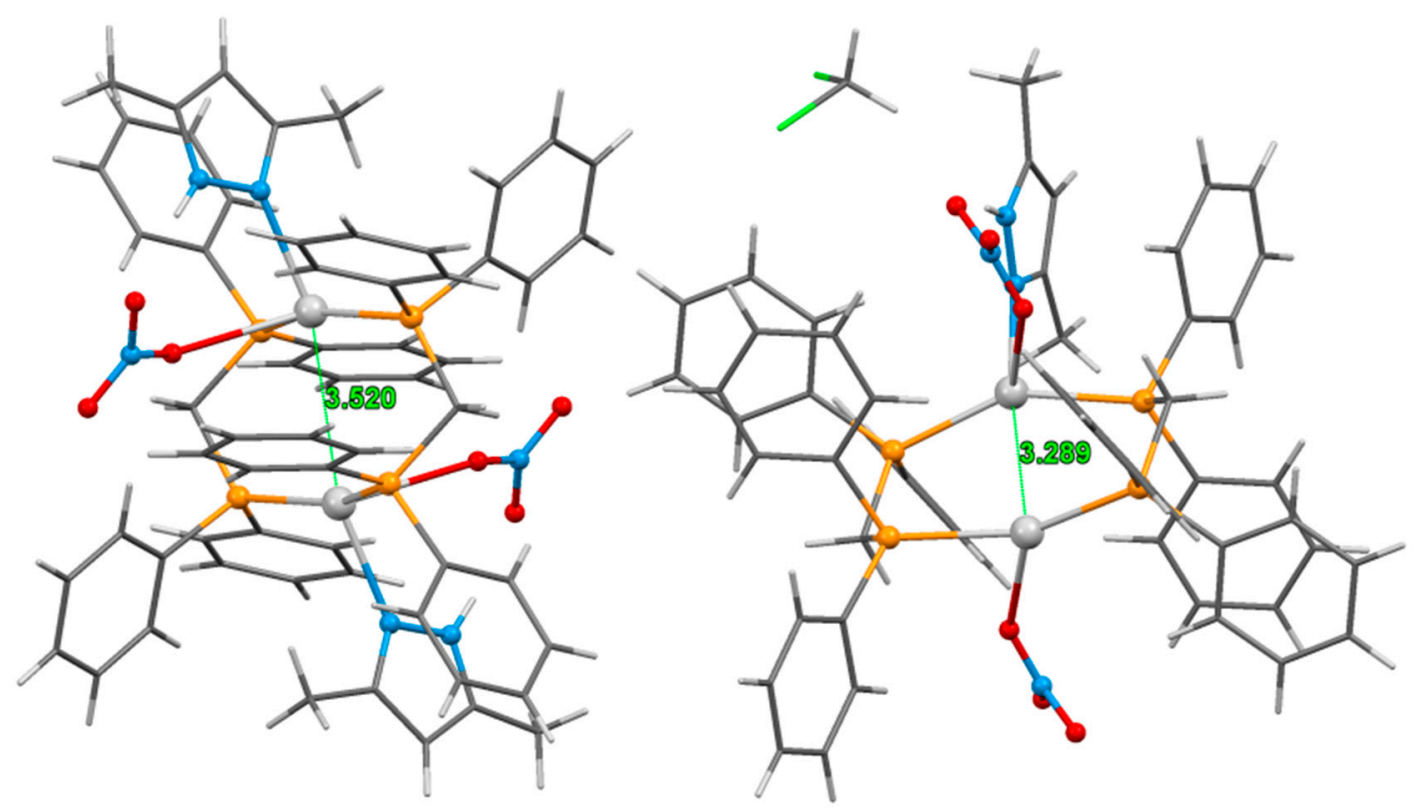

Figure 4. XRD structure of the co-crystal $\mathbf{2 a} / \mathbf{2} \mathbf{b}$ and dichloromethane (DCM) molecule (carbon, hydrogen, and chlorine atoms are shown as sticks).

\subsection{Photophysical Properties}

The only pure compounds $\mathbf{1}$ and $\mathbf{2} \mathbf{a}$, in contrast to $\mathbf{2} \mathbf{b}$, were isolated. All experimental studies (UV-Vis and photoluminescence) were performed for these complexes. The theoretical investigations (TD-DFT) were performed for all possible types of complexes $(\mathbf{1}, \mathbf{2} \mathbf{a}$, and $\mathbf{2 b})$.

The TD-DFT calculations were performed for complexes $\mathbf{1}$ and $\mathbf{2 b}$ keeping their local $C_{i}$ symmetry. The presence of the inversion center led to the appearance of the symmetry forbidden $\mathrm{A}_{\mathrm{g}}$, and the symmetry allowed $A_{u}$ transitions. This is why only symmetry allowed $A_{u}$ transitions are discussed further. The lowest excitations of 1 were $S_{1}$ and $S_{2}$ with energies of 4.18 and $5.01 \mathrm{eV}(296$ and $247 \mathrm{~nm}$; Table S1), respectively. The $\mathrm{S}_{1}$ had a pronounced $\mathrm{LC}^{\mathrm{NO} 3}$ character with a negligible impact of $\mathrm{Ag}$ atoms (Figure S1, Table S1). The oscillator strength (f) value of 0.0002 demonstrates that this excitation was ineffective (dark state). In contrast, the second singlet transition $(5.01 \mathrm{eV}, \mathrm{f}=0.1853$ ) had a metal-centered (MC) nature (Figure 5). Upon this excitation, the electron leaves the Ag-P $\sigma$ bonding orbital (impacts of $\mathrm{Ag}-40 \%$ and $\mathrm{P}-36 \%$, Table S1) and locates on the intramolecular $\mathrm{Ag}-\mathrm{Ag}$ bond, which is generated by the empty $5 p_{z}$ orbitals of the silver cations. The vertical excitation energies for the three lowest triplets were 3.70, 4.30, and $4.60 \mathrm{eV}(334,287$, and $269 \mathrm{~nm})$, respectively. The first two triplets were of a $\mathrm{LC}^{\mathrm{NO} 3}$ nature, and the impact of metals and dpcym ligands appeared in the $\mathrm{T}_{3}$ state. The $T_{3}$ had an excellent match to the $S_{2}$ state; their similarity was $\mathrm{s}_{\mathrm{H}}=0.91$ and $\mathrm{s}_{\mathrm{E}}=0.95$. Along with the oscillator strengths, this indicates a high probability for the excitation of $\mathbf{1}$ directly to $S_{2}$ state, $S_{2} \rightarrow$ $\mathrm{T}_{3}$ interconversion, followed by the triplet emission from the $\mathrm{T}_{3}$ state, which describes the emission observed (vide infra, Figure S13). 


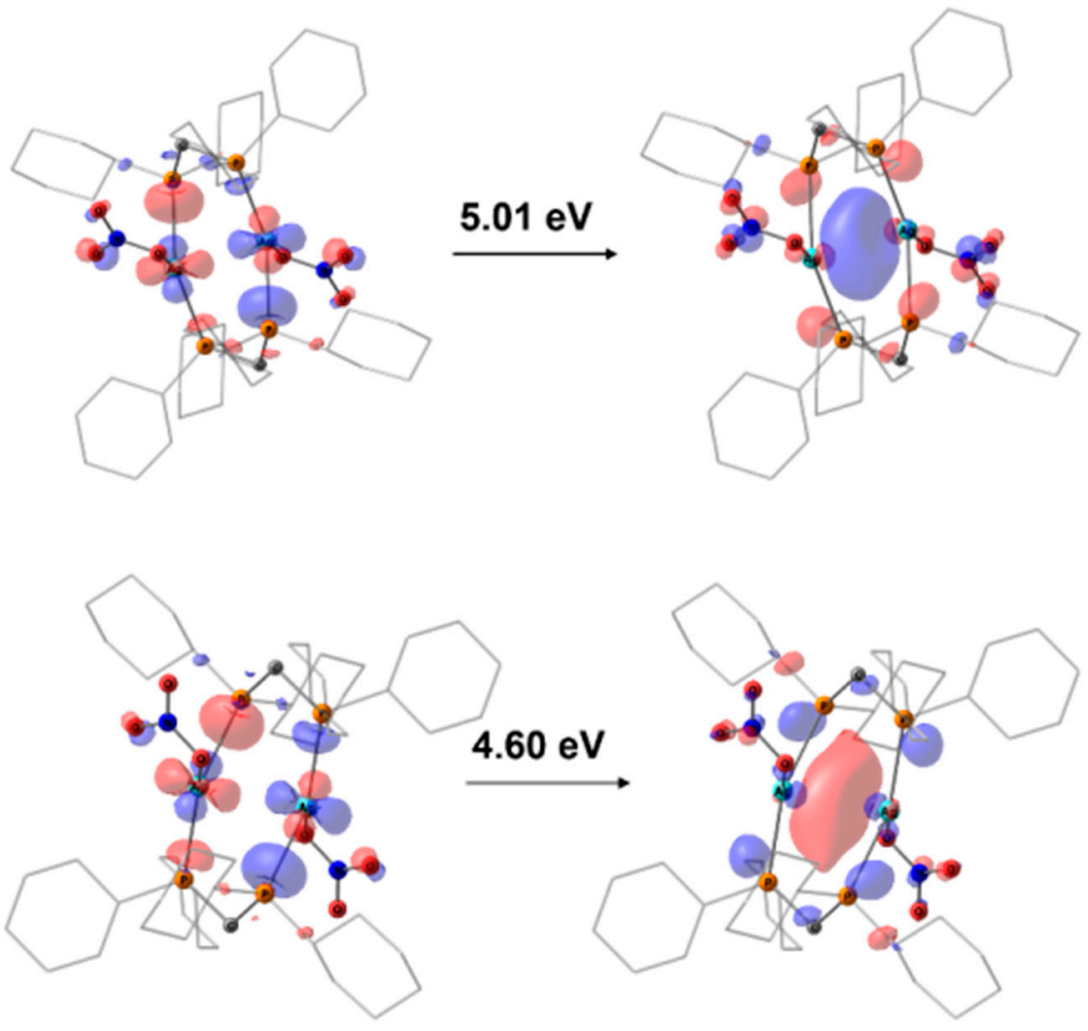

Figure 5. Highest occupied natural transition orbital (HONTO) and lowest unoccupied natural transition orbital (LUNTO) for the $S_{0} \rightarrow S_{2}$ (top) and $S_{0} \rightarrow T_{3}$ (bottom) transition in complex $\mathbf{1}$ as the isosurface at 0.05 a.u.

The excitation pattern of the complex $\left[\mathrm{Ag}\left(\mathrm{Me}_{2} \mathrm{Pz}^{\mathrm{H}}\right)(\mathrm{dppm})\right]_{2}\left(\mathrm{NO}_{3}\right)_{2}(\mathbf{2} \mathbf{b})$ differed from that observed for $[\mathrm{Ag}(\mathrm{dcypm})]_{2}\left(\mathrm{NO}_{3}\right)_{2}$ (1). The first singlet $(4.16 \mathrm{eV}, 298 \mathrm{~nm}, \mathrm{f}=0.2354$; Figure 6) possessed a comparable impact to the hole from metals (35\%) and phosphorus atoms (from dppm, 33\%) with some contribution from $10 \%$ dimethylpyrazole (Figure S2, Table S2). However, the excited electron was located mainly on the organic part of the dppm ligand (64\%), indicating the charge transfer character of this transition. Therefore, it could be ascribed to $\left(\mathrm{Ag}^{+}+\mathrm{P}^{\mathrm{dppm}}+\mathrm{N}^{\text {Pyrazole }}\right) \rightarrow\left(\mathrm{Ph}+\mathrm{CH}_{2}\right)^{\mathrm{dppm}}$ charge transfer. The electron density at the Ag $\cdots \mathrm{Ag}$ intramolecular contact was still present in the excited $\mathrm{S}_{1}$ state. Still, the contribution of Ag atoms to the excited state dropped by three times compared to the $S_{2}$ of complex 1 , and as a result, it could be observed only at the 0.03 a.u. isosurface (Figure S2). These data indicate the role of the dimethylpyrazole ligand in the metal-induced electronic transitions. The four lowest triplet states for $\mathbf{2} \mathbf{b}$ were the ${ }^{3} \mathrm{LC}$ states of Ph substituents in dppm ligands, while $\mathrm{T}_{5}$ was the ${ }^{3} \mathrm{LC}^{\mathrm{NO} 3}$ state (Figure S2). The $\mathrm{T}_{6}$ of MLCT nature is the state coupled with the $\mathrm{S}_{1}$ excitation, having high similarity $\left(\mathrm{s}_{\mathrm{H}}=0.91\right.$ and $\left.\mathrm{s}_{\mathrm{E}}=0.90\right)$ to the $\mathrm{S}_{0} \rightarrow \mathrm{T}_{6}$ transition energy $4.02 \mathrm{eV}(308 \mathrm{~nm})$ (Figure 6). Similar behavior was observed in the case of dinuclear silver pyrazolates with $\mathrm{PCy}_{3}$ and $\mathrm{PPh}_{3}$ ligands [35].

The TD-DFT analysis of $[\mathrm{Ag}(\mathrm{dppm})]_{2}\left(\mathrm{Me}_{2} \mathrm{Pz}^{\mathrm{H}}\right)\left(\mathrm{NO}_{3}\right)_{2}$ (2a) excitations led to nearly the same pattern, except the disappearance of symmetry forbidden states, which led to doubling of the number of corresponding electronic transitions. At that, the $S_{1}$ and $S_{2}$ states both possess mixed MLCT $\left(\mathrm{Ag}^{+}+\right.$ $\left.\mathrm{P}^{\mathrm{dppm}}+\mathrm{N}^{\text {Pyrazole }}\right) \rightarrow\left(\mathrm{Ph}+\mathrm{CH}_{2}\right)^{\mathrm{dppm}}+\mathrm{LC}^{\mathrm{NO} 3}$ character with close excitation energies and oscillator strengths $\left(4.11 \mathrm{eV}, 301 \mathrm{~nm}, \mathrm{f}=0.0994\right.$ for $\mathrm{S}_{1}$ and $4.17 \mathrm{eV}, 297 \mathrm{~nm}, \mathrm{f}=0.1605$ for $\mathrm{S}_{2}$ ) as a result of mixing with symmetry forbidden $\mathrm{A}_{\mathrm{G}}{ }^{1} \mathrm{LC}^{\mathrm{NO} 3}$ state upon loss of symmetry (Figure 7, Table S3). Despite this mixing, the simulated excitation spectra were the same for $\mathbf{2 a}$ and $\mathbf{2 b}$ (Tables S2 and S3, Figure S3). For triplet transitions due to the unsymmetrical structure, the eight lowest triplets were ${ }^{3} \mathrm{LC}$ states of Ph substituents in dppm ligands, and $\mathrm{T}_{9}-\mathrm{T}_{10}$ are ${ }^{3} \mathrm{LC}^{\mathrm{NO}} 3$ states, while $\mathrm{T}_{11}$ and $\mathrm{T}_{12}$ were MLCT states. 
Due to the mixing of singlet states with $\mathrm{LC}^{\mathrm{NO} 3}$ transition, the discussed singlet and triplet states had a low similarity. Still, if we ignore the $\mathrm{NO}_{3}$ group's contributions, the similarity for $\mathrm{S}_{2}-\mathrm{T}_{11}$ was $\mathrm{s}_{\mathrm{H}}=0.83$, $\mathrm{s}_{\mathrm{E}}=0.79$ and for $\mathrm{S}_{2}-\mathrm{T}_{12}$ it was $\mathrm{s}_{\mathrm{H}}=0.84, \mathrm{~s}_{\mathrm{E}}=0.75$. Based on these, practically the same conclusion can be made as for $\mathbf{2} \mathbf{b}$. The lowest singlet excitation should lead to the high energy triplets $T_{11}-T_{12}$ that is likely to interconvert to the lower ${ }^{3} \mathrm{LC}$ states of dppm' $\mathrm{Ph}$ substituents, which in turn has a trend to non-emissive relaxation at room temperature [35-37], but could be stabilized at $77 \mathrm{~K}$.

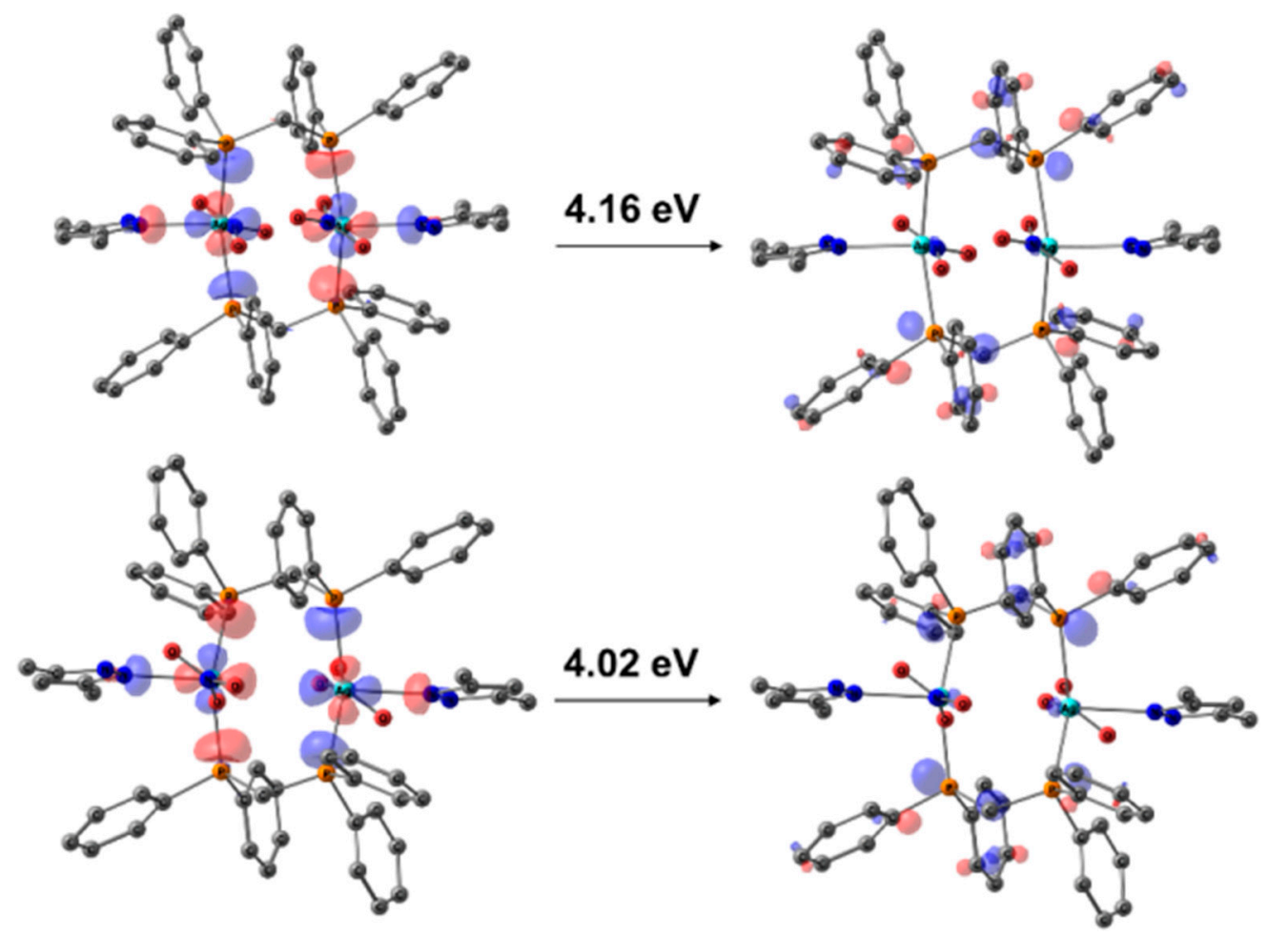

Figure 6. HONTO and LUNTO for the $S_{0} \rightarrow S_{1}$ and $S_{0} \rightarrow T_{6}$ in complex $\mathbf{2} \mathbf{b}$ as the isosurface at 0.05 au.

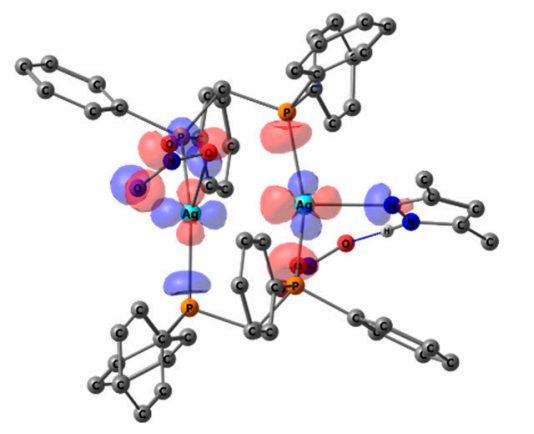

$4.17 \mathrm{eV}$
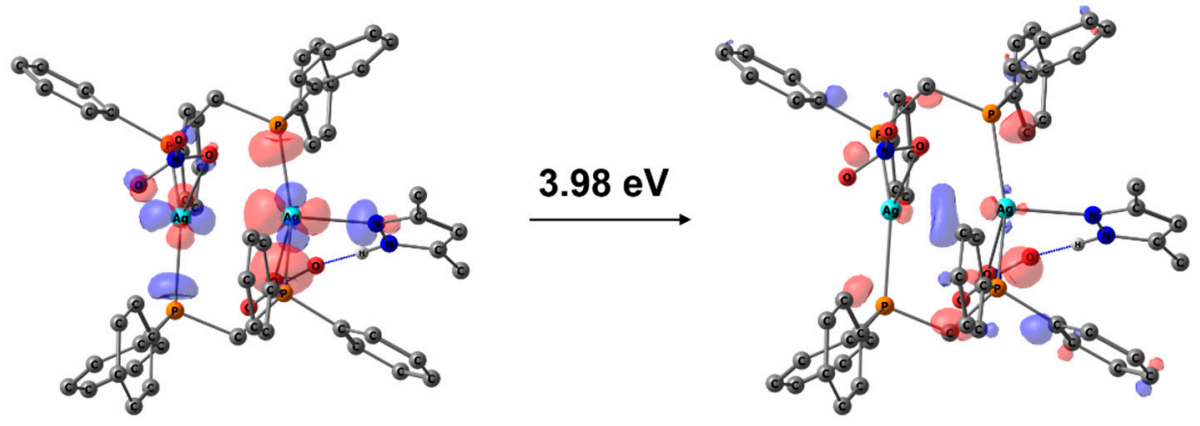

Figure 7. HONTO and LUNTO for the $\mathrm{S}_{0} \rightarrow \mathrm{S}_{2}$ and $\mathrm{S}_{0} \rightarrow \mathrm{T}_{11}$ in complex $2 \mathbf{a}$ as the isosurface at $0.05 \mathrm{au}$. 
The UV-Vis spectra of $\mathbf{1}$ and $\mathbf{2 a}$ were measured in $\mathrm{CH}_{2} \mathrm{Cl}_{2}$ (Figure 8). Complex $\mathbf{1}$ demonstrated an intense absorbance band at $267 \mathrm{~nm}\left(\varepsilon=13350 \mathrm{~cm}^{-1} \mathrm{M}^{-}\right)$. This band can be attributed to the transition with a metal-centered (MC) character originating from intramolecular $\mathrm{Ag}(\mathrm{I})-\mathrm{Ag}(\mathrm{I})$ interactions [9]. The presence of the nitrate anion in complex 1 resulted in the non-intensive tail around $300 \mathrm{~nm}$, which correlated with the absorption spectrum of the aqueous solution of silver nitrate.

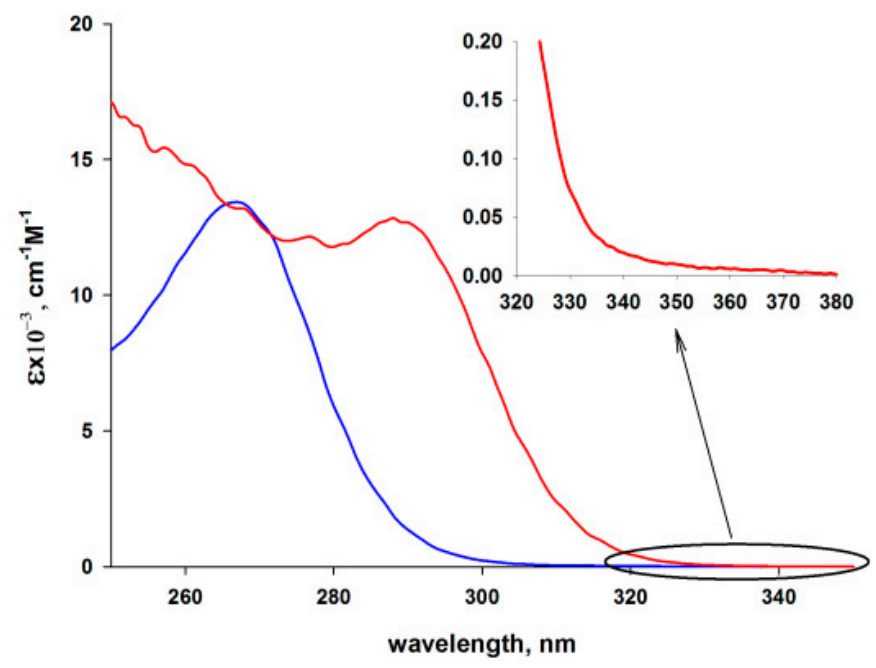

Figure 8. Absorption spectra of complexes 1 (blue) and 2a (red) in $\mathrm{CH}_{2} \mathrm{Cl}_{2}$ solution.

UV-Vis spectrum of compound 2a showed a broad, intense band at $288 \mathrm{~nm}\left(\varepsilon=12800 \mathrm{~cm}^{-1} \mathrm{M}^{-1}\right)$ with a long tail at ca. $335 \mathrm{~nm}$, which can be assigned to the charge-transfer (MLCT or LLCT) transitions. Additionally, in the high energy region $(<280 \mathrm{~nm})$, weakly resolved bands with the contribution from several bands of close energies were observed. This band could be assigned only to the transitions of the $\pi \rightarrow \pi^{*}$ character within the Ph substituents in bisphosphine and pyrazole ligands.

The emission spectra of complexes 1 and 2a were studied in $\mathrm{CH}_{2} \mathrm{Cl}_{2}$ solution and the solid state (Figure 9). The room temperature (RT) emission spectrum of complex $\mathbf{1}$ in the solution displayed two bands at 370 and $390 \mathrm{~nm}$, respectively, which can be assigned to the emission from the electronically excited states of MC nature. The emission bands of $\mathbf{1}$ in the solid state were in the same position. Temperature decrease led to the non-significant redistribution of the solid sample band's intensities. The triplet state decays also demonstrate this mixed emissive behavior. The phosphorescence decay of $\mathbf{1}$ both in the solution and in solid state at RT and $77 \mathrm{~K}$ can only be fitted with bi-exponential function. In the $\mathrm{CH}_{2} \mathrm{Cl}_{2}$ solution at $\mathrm{RT}$, lifetimes were 1 and $10 \mu \mathrm{s}$. In the solid state lifetimes, $\tau$ was practically independent of temperature being ca. 2 and $16 \mu$ s. These data demonstrate that complex 1 possessed the same photoluminescence both in solution and solid state. Complex $2 \mathbf{a}$ in the acetonitrile solution possessed phosphorescence bands at 365 and $410 \mathrm{~nm}$ (for both $\tau=8.7 \mu \mathrm{s}$ ). In the solid state at RT, complex $2 \mathbf{a}$ showed an unstructured band at $380 \mathrm{~nm}$ of CT nature $(\tau=9 \mu \mathrm{s})$. Interestingly, at $77 \mathrm{~K}$, the presence of a new intense band at $440 \mathrm{~nm}$ was observed $(\tau=37 \mu \mathrm{s})$. The position of the band observed at RT shifted from 380 to $390 \mathrm{~nm}$ at $77 \mathrm{~K}$, but the lifetime of this emission was not dependent on the temperature $(8.9 \mu \mathrm{s})$. The results of calculations (vide supra) showed that the $\mathrm{T}_{1}-\mathrm{T}_{8}$ states were of LC nature within Ph substituents. As we have shown for structurally similar silver pyrazolate/dppm complexes, these states are not emissive due to the intersection of their energy surface with the ground state, which allows effective non-radiative relaxation [35-37]. The emission observed at $298 \mathrm{~K}$ can be ascribed to the system relaxation from $\mathrm{T}_{11-12}(3.98-4.21 \mathrm{eV})$ and higher states of $\left(\left(\mathrm{M}+\mathrm{L}^{\mathrm{P}+\mathrm{N}}\right) \mathrm{L}^{\mathrm{dppm}} \mathrm{CT}\right)$ nature. The temperature decrease led to the stabilization of triplet states of the $\mathrm{LC}^{\mathrm{Ph}}$ nature and these channels possess a main influence on the emission of $2 \mathbf{a}$ observed at $77 \mathrm{~K}$. 


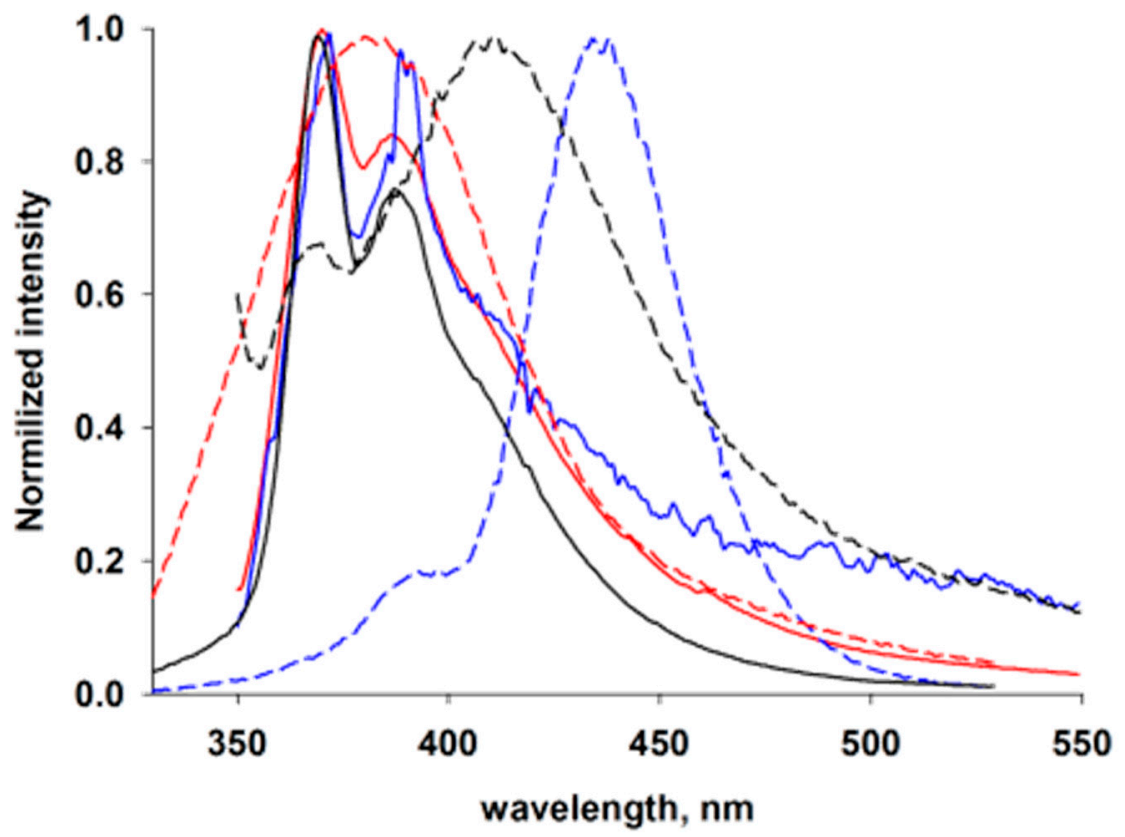

Figure 9. Normalized emission $\left(\lambda_{\text {exc }}=320 \mathrm{~nm}\right.$ ) spectra of complexes $\mathbf{1}$ (solid line) and 2a (dashed line) in the solution (black) and solid state at $298 \mathrm{~K}$ (red) and $77 \mathrm{~K}$ (blue).

\section{Conclusions}

The reaction of silver nitrate with bisphosphines in the presence of 3,5-dimethylpyrazole gave new examples of dinuclear silver(I) complexes of different composition $[\mathrm{Ag}(\mathrm{dcypm})]_{2}\left(\mathrm{NO}_{3}\right)_{2}(\mathbf{1})$, $[\mathrm{Ag}(\mathrm{dppm})]_{2}\left(\mathrm{NO}_{3}\right)_{2}\left(\mathrm{Me}_{2} \mathrm{Pz}^{\mathrm{H}}\right)(\mathbf{2 a})$, and $\left[\mathrm{Ag}\left(\mathrm{Me}_{2} \mathrm{Pz}^{\mathrm{H}}\right)(\mathrm{dppm})\right]_{2}\left(\mathrm{NO}_{3}\right)_{2}(\mathbf{2 a})$. This suggests that the steric repulsion of bulky cyclohexyl substituents does not allow coordination of additional pyrazole ligand to the silver atoms in $[\mathrm{Ag}(\mathrm{dcypm})]_{2}\left(\mathrm{NO}_{3}\right)_{2}$. Complex $2 \mathbf{a}$ was obtained by the crystallization of $\mathbf{2 b}$ from a diluted solution in accordance with low solubility accompanied by the elimination of one pyrazole molecule. For all complexes, non-typical $\kappa^{1}$ coordination of the nitrate anion was observed, which led to a significant distortion of the central eight-member cycle $[\mathrm{AgPCP}]_{2}$ in comparison to related silver bisphosphine complexes. Complexes possessed phosphorescence both in the solution and in the

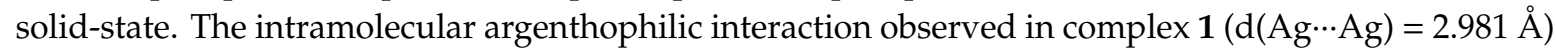
introduces the main excitation channel in which an electron leaves the Ag-P bond orbital and locates on the intramolecular Ag-Ag bond (metal-centered character). The coordination of dimethylpyrazole to $\mathrm{Ag}(\mathrm{I})$ in complex 2a led to the elongation of the $\mathrm{Ag} \cdot \cdots \mathrm{Ag}$ distance (3.218 $\mathrm{A})$. Complex 2a exhibited a phosphorescence originating from the charge-transfer from the ${ }^{3}\left(\mathrm{M}+\mathrm{L}^{\mathrm{P}+\mathrm{N}}\right) \mathrm{L}^{\mathrm{Ph}} \mathrm{CT}$ state at room temperature. At $77 \mathrm{~K}$, the emission was split into two components: ${ }^{3}\left(\mathrm{M}+\mathrm{L}^{\mathrm{P}+\mathrm{N}}\right) \mathrm{L}^{\mathrm{Ph}} \mathrm{CT}$ and ${ }^{3} \mathrm{LC}^{\mathrm{Ph}}$ transitions. According to the TD-DFT calculations, the coordination of dimethylpyrazole to the metal atom mainly affects the energy of transition.

Supplementary Materials: The following are available online at http://www.mdpi.com/2073-4352/10/10/881/s1, Figure S1: Natural transition orbital's of $\mathbf{1}$ as the isosurface at 0.05 a.u.; Table S1: Computed characteristics of the excited states of $\mathbf{1}$. For analysis of fragment impacts (in \%) to the ground state (hole) and excited state (electron), complex was divided to fragments of all $\mathrm{Ag}$ atoms, all $\mathrm{P}$ atoms, nitrate anions, and all atoms of dcypm ligand except P.; Figure S2: Natural transition orbital's of 2 as the isosurface at 0.05 a.u. except for S1 and T6; Table S2: Computed characteristics of the $A_{u}$ symmetry excited states of 2 . For analysis of fragment impacts (in \%) to the ground state (hole) and excited state (electron), the complex was divided to fragments of all Ag atoms, all $\mathrm{P}$ atoms, nitrate anions, pyrazolates, and all atoms of dppm ligand except P.; Figure S3: Natural transition orbital's of $2 \mathbf{a}$ as the isosurface at 0.05 a.u., Table S3. Computed characteristics of the AU symmetry excited states of 2a; Figure S4: Phosphorescence decay by delay of complex 1 at $\mathrm{RT}$ in $\mathrm{CH}_{2} \mathrm{Cl}_{2}$ solution (left) and solid state (right); Figure S5: Phosphorescence decay by delay of complex 1 in the solid state at $77 \mathrm{~K}$; Figure S6. Phosphorescence decay by delay of complex 2a at RT in $\mathrm{CH}_{2} \mathrm{Cl}_{2}$ solution (left) and solid state (right); Figure S7: Phosphorescence decay by delay of complex $2 \mathbf{a}$ in the solid state at $77 \mathrm{~K}$ (measured at $390 \mathrm{~nm}$ ); Figure S8: Phosphorescence decay 
by delay of complex 2a in the solid state at $77 \mathrm{~K}$ (measured at $440 \mathrm{~nm}$ ); Figure S9: The ${ }^{1} \mathrm{H}$ NMR spectrum of complex 1 in $\mathrm{CD}_{2} \mathrm{Cl}_{2}$; Figure S10: The ${ }^{31} \mathrm{P}\left\{{ }^{1} \mathrm{H}\right\}$ NMR spectrum of complex 1 in $\mathrm{CD}_{2} \mathrm{Cl}_{2}$; Figure S11: The $1 \mathrm{H}$ NMR spectrum of complex 2a in $\mathrm{CD}_{3} \mathrm{CN}$; Figure S13: Schematic Jablonski diagram for 1, 2a, 2b. Presumably active states indicated by solid lines; Figure S14: Comparison of X-ray and DFT geometry of $\mathrm{Ag}_{2} \mathrm{P}_{4}\left(\mathrm{NO}_{3}\right)_{2}$ core for $\mathbf{1}, \mathbf{2 a}$ and $\mathbf{2 b}$. Atoms of $\mathrm{X}$-ray structure is shaded, DFT structure is colored. Ag-cyan, P-orange, C-gray, $\mathrm{O}$-red, N-blue; Figure S15: Excitation spectra of $\mathbf{1}$ in $\mathrm{CH}_{2} \mathrm{Cl}_{2}$ solution (left, em. on 370 and 390), and in the solid state (right, em. 370); Figure S16: Excitation spectra of $2 \mathrm{a}$ in $\mathrm{CH}_{2} \mathrm{Cl}_{2}$ solution (left, em. on 410) and in the solid state (right, em. on 380); Figure S17: IR spectrum of complex 2a in KBr pellets; Figure S18: The simulated electronic spectra of $\mathbf{1}, \mathbf{2} \mathbf{a}$, and $\mathbf{2} \mathbf{b}$. The 200 lowest energy singlet transitions were considered, and full width at half maximum was set to 40; Figure S19: ${ }^{1} \mathrm{H}$ NMR spectrum of the precipitate obtained in the case of interaction silver nitrate with dppm and $\mathrm{Me}_{2} \mathrm{Pz}^{\mathrm{H}}$, demonstrating $\mathrm{Ag} /\left(\mathrm{Me}{ }_{2} \mathrm{PzH}\right) / \mathrm{dppm}=1 / 1 / 1$ ratio, $\mathrm{CD}_{2} \mathrm{Cl}_{2}$; Figure S20: ${ }^{1} \mathrm{H}$ NMR spectrum of the precipitate obtained in the case of interaction silver nitrate with dppm and $\mathrm{Me}_{2} \mathrm{Pz}^{\mathrm{H}}$, demonstrating $\mathrm{Ag} /\left(\mathrm{Me}_{2} \mathrm{PzH}\right) / \mathrm{dppm}=1 / 1 / 1$ ratio, $\mathrm{CD}_{3} \mathrm{OD}$.

Author Contributions: Synthetic experiments, K.F.B.; Experiments and writing original draft, A.A.T.; Calculations and visualizations, O.A.F.; XRD studies, A.F.S.; Photoluminescence, A.A.A.; Writing review \& editing, A.A.T., O.A.F., and E.S.S. All authors have read and agreed to the published version of the manuscript.

Funding: This work was financially supported by the Russian Foundation for Basic Research (RFBR grant no. 18-33-20060).

Acknowledgments: NMR and XRD measurements were performed using the equipment of the Center for Molecular Composition Studies at the INEOS RAS and were supported by the Ministry of Science and Higher Education of the Russian Federation. Photophysical properties were measured using the equipment of the Center of Physical Methods of Investigation at the IPCE RAS.

Conflicts of Interest: The authors declare that there is no conflicts of interest.

\section{References}

1. Yam, V.W.; Au, V.K.; Leung, S.Y. Light-Emitting Self-Assembled Materials Based on d(8) and d(10) Transition Metal Complexes. Chem. Rev. 2015, 115, 7589-7728. [CrossRef]

2. Schmidbaur, H.; Schier, A. Argentophilic interactions. Angew. Chem. Int. Ed. 2015, 54, 746-784. [CrossRef]

3. Dolan, N.S.; Scamp, R.J.; Yang, T.; Berry, J.F.; Schomaker, J.M. Catalyst-Controlled and Tunable, Chemoselective Silver-Catalyzed Intermolecular Nitrene Transfer: Experimental and Computational Studies. J. Am. Chem. Soc. 2016, 138, 14658-14667. [CrossRef]

4. Alderson, J.M.; Corbin, J.R.; Schomaker, J.M. Tunable, Chemo- and Site-Selective Nitrene Transfer Reactions through the Rational Design of Silver(I) Catalysts. Acc. Chem. Res. 2017, 50, 2147-2158. [CrossRef]

5. Mak, C.L.; Bostick, B.C.; Yassin, N.M.; Campbell, M.G. Argentophilic Interactions in Solution: An EXAFS Study of Silver(I) Nitrene Transfer Catalysts. Inorg. Chem. 2018, 57, 5720-5722. [CrossRef]

6. Grachova, E.V. Design of Supramolecular Cluster Compounds of Copper Subgroup Metals Based on Polydentate Phosphine Ligands. Russ. J. Gen. Chem. 2019, 89, 1102-1114. [CrossRef]

7. Ho, D.M.; Bau, R. Preparation and structural characterization of $\left[\mathrm{Ag}_{2}(\mathrm{dpm})_{2}\left(\mathrm{NO}_{3}\right)_{2}\right]$ and $\left[\mathrm{Ag}_{4}(\mathrm{dpm})_{4}\left(\mathrm{NO}_{3}\right)_{2}\right]^{2+}$ $\left[\mathrm{PF}_{6}\right]^{2-}$ : Conformational flexibility in the $\mathrm{M}_{2} \mathrm{P}_{4}$ core structure of bis(diphenylphosphino)methane complexes. Inorg. Chem. 1983, 22, 4073-4079. [CrossRef]

8. Che, C.-M.; Kwong, H.-L.; Yam, V.W.-W.; Cho, K.-C. Spectroscopic properties and redox chemistry of the phosphorescent excited state of $\left[\mathrm{Au}_{2}(\mathrm{dppm})_{2}\right]^{2+}[\mathrm{dppm}=$ bis(diphenylphosphino)methane $]$. J. Chem. Soc. Chem. Commun. 1989, 885-886. [CrossRef]

9. Che, C.-M.; Tse, M.-C.; Chan, M.C.W.; Cheung, K.-K.; Phillips, D.L.; Leung, K.-H. Spectroscopic Evidence for Argentophilicity in Structurally Characterized Luminescent Binuclear Silver(I) Complexes. J. Am. Chem. Soc. 2000, 122, 2464-2468. [CrossRef]

10. Lin, Y.Y.; Lai, S.W.; Che, C.M.; Fu, W.F.; Zhou, Z.Y.; Zhu, N. Structural variations and spectroscopic properties of luminescent mono- and multinuclear silver(I) and copper(I) complexes bearing phosphine and cyanide ligands. Inorg. Chem. 2005, 44, 1511-1524. [CrossRef]

11. Piché, D.; Harvey, P.D. The lowest energy excited states of the binuclear silver(I) halide complexes, $\mathrm{Ag}_{2}(\mathrm{dmb})_{2} \mathrm{X}_{2}$. Metal-centered or charge transfer states? Canad. J. Chem. 1994, 72, 705-713. [CrossRef]

12. Chan, J. Studies of metal binding reactions in metallothioneins by spectroscopic, molecular biology, and molecular modeling techniques. Coord. Chem. Rev. 2002, 233-234, 319-339. [CrossRef] 
13. Chen, Y.; Yang, T.; Pan, H.; Yuan, Y.; Chen, L.; Liu, M.; Zhang, K.; Zhang, S.; Wu, P.; Xu, J. Photoemission mechanism of water-soluble silver nanoclusters: Ligand-to-metal-metal charge transfer vs strong coupling between surface plasmon and emitters. J. Am. Chem. Soc. 2014, 136, 1686-1689. [CrossRef]

14. Yang, T.; Dai, S.; Tan, H.; Zong, Y.; Liu, Y.; Chen, J.; Zhang, K.; Wu, P.; Zhang, S.; Xu, J.; et al. Mechanism of Photoluminescence in Ag Nanoclusters: Metal-Centered Emission versus Synergistic Effect in Ligand-Centered Emission. J. Phys. Chem. C 2019, 123, 18638-18645. [CrossRef]

15. Blake, A.J.; Donamaria, R.; Lippolis, V.; Lopez-de-Luzuriaga, J.M.; Manso, E.; Monge, M.; Olmos, M.E. Influence of crown thioether ligands in the structures and of perhalophenyl groups in the optical properties of complexes with argentoaurophilic interactions. Inorg. Chem. 2014, 53, 10471-10484. [CrossRef]

16. Donamaria, R.; Lippolis, V.; Lopez-de-Luzuriaga, J.M.; Monge, M.; Nieddu, M.; Olmos, M.E. Influence of the Number of Metallophilic Interactions and Structures on the Optical Properties of Heterometallic Au/Ag Complexes with Mixed-Donor Macrocyclic Ligands. Inorg. Chem. 2018, 57, 11099-11112. [CrossRef]

17. Ai, P.; Mauro, M.; Gourlaouen, C.; Carrara, S.; De Cola, L.; Tobon, Y.; Giovanella, U.; Botta, C.; Danopoulos, A.A.; Braunstein, P. Bonding, Luminescence, Metallophilicity in Linear $\mathrm{Au}_{3}$ and $\mathrm{Au}_{2} \mathrm{Ag}$ Chains Stabilized by Rigid Diphosphanyl NHC Ligands. Inorg. Chem. 2016, 55, 8527-8542. [CrossRef]

18. Sheldrick, G. SHELXT-Integrated space-group and crystal-structure determination. Acta Crystallogr. Sect. A. 2015, 71, 3-8. [CrossRef]

19. Sheldrick, G. Crystal structure refinement with SHELXL. Acta Crystallogr. Sect. C. 2015, 71, 3-8. [CrossRef]

20. Dolomanov, O.V.; Bourhis, L.J.; Gildea, R.J.; Howard, J.A.K.; Puschmann, H. OLEX2: A complete structure solution, refinement and analysis program. J. Appl. Crystallogr. 2009, 42, 339-341. [CrossRef]

21. Adamo, C.; Barone, V. Toward reliable density functional methods without adjustable parameters: The PBE0 model. J. Chem. Phys. 1999, 110, 6158-6170. [CrossRef]

22. Andrae, D.; Häußermann, U.; Dolg, M.; Stoll, H.; Preuß, H. Energy-adjustedab initio pseudopotentials for the second and third row transition elements. Theor. Chim. Acta 1990, 77, 123-141. [CrossRef]

23. Weigend, F.; Ahlrichs, R. Balanced basis sets of split valence, triple zeta valence and quadruple zeta valence quality for H to Rn: Design and assessment of accuracy. Phys. Chem. Chem. Phys. 2005, 7, 3297-3305. [CrossRef]

24. Frisch, M.J.; Trucks, G.W.; Schlegel, H.B.; Scuseria, G.E.; Robb, M.A.; Cheeseman, J.R.; Scalmani, G.; Barone, V.; Mennucci, B.; Petersson, G.A.; et al. Gaussian 09, Revision B.01; Gaussian Inc.: Wallingford, CT, USA, 2009.

25. Lu, T.; Chen, F. Multiwfn: A multifunctional wavefunction analyzer. J. Comput. Chem. 2012, 33, 580-592. [CrossRef]

26. Chen, R.; Tang, Y.; Wan, Y.; Chen, T.; Zheng, C.; Qi, Y.; Cheng, Y.; Huang, W. Promoting Singlet/triplet Exciton Transformation in Organic Optoelectronic Molecules: Role of Excited State Transition Configuration. Sci. Rep. 2017, 7, 6225. [CrossRef]

27. Das, S.; Sharma, S.; Singh, H.B.; Butcher, R.J. Metallophilic Mercuraazamacrocycles Derived from Bis $\{6$-formyl(2,3,4-trimethoxy)phenyl\}mercury: Reactivity with d10 and d8 Metal Ions. Eur. J. Inorg. Chem. 2018, 2018, 4093-4105. [CrossRef]

28. Titov, A.A.; Filippov, O.A.; Smol'yakov, A.F.; Averin, A.A.; Shubina, E.S. Synthesis, structures and luminescence of multinuclear silver(I) pyrazolate adducts with 1,10-phenanthroline derivatives. Dalton Trans. 2019, 48, 8410-8417. [CrossRef]

29. Emashova, S.K.; Titov, A.A.; Filippov, O.A.; Smol'yakov, A.F.; Titova, E.M.; Epstein, L.M.; Shubina, E.S. Luminescent $\mathrm{Ag}$ I Complexes with 2,2'-Bipyridine Derivatives Featuring [Ag- $\left(\mathrm{CF}_{3}\right)_{2}$ Pyrazolate $]_{4}$ Units. Eur. J. Inorg. Chem. 2019, 2019, 4855-4861. [CrossRef]

30. Desiraju, G.R. Hydrogen bridges in crystal engineering: Interactions without borders. Acc. Chem. Res. 2002, 35, 565-573. [CrossRef]

31. Steiner, T. The Hydrogen Bond in the Solid State. Angew. Chem. Int. Ed. 2002, 41, 48-76. [CrossRef]

32. Tiekink, E.R.T. Bis- $\mu$-[methylenebis(diphenylphosphine)]-dinitratodisilver(I) dichloroform solvate. Acta Crystallogr. Sect. C. 1990, 46, 235-238. [CrossRef]

33. Cui, Y.-Z.; Yuan, Y.; Li, Z.-F.; Liu, M.; Jin, Q.-H.; Jiang, N.; Cui, L.-N.; Gao, S. From ring, chain to network: Synthesis, characterization, luminescent properties of silver(I) complexes constructed by diphosphine ligands and various N-donor ligands. Polyhedron 2016, 112, 118-129. [CrossRef] 
34. Qiu, Q.-M.; Huang, X.; Zhao, Y.-H.; Liu, M.; Jin, Q.-H.; Li, Z.-F.; Zhang, Z.-W.; Zhang, C.-L.; Meng, Q.-X. Synthesis, structure and terahertz spectra of six $\mathrm{Ag}(\mathrm{I})$ complexes of bis(diphenylphosphino)methane with 4,4'-bipyridine and its derivations. Polyhedron 2014, 83, 16-23. [CrossRef]

35. Titov, A.A.; Filippov, O.A.; Smol'yakov, A.F.; Baranova, K.F.; Titova, E.M.; Averin, A.A.; Shubina, E.S. Dinuclear $\mathrm{Cu}(\mathrm{I})$ and $\mathrm{Ag}(\mathrm{I})$ Pyrazolates Supported with Tertiary Phosphines: Synthesis, Structures, and Photophysical Properties. Eur. J. Inorg. Chem. 2019, 2019, 821-827. [CrossRef]

36. Titov, A.A.; Filippov, O.A.; Smol'yakov, A.F.; Averin, A.A.; Shubina, E.S. Copper(I) complex with BINAP and 3,5-dimethylpyrazole: Synthesis and photoluminescent properties. Mendeleev Commun. 2019, 29, 570-572. [CrossRef]

37. Titov, A.A.; Filippov, O.A.; Smol'yakov, A.F.; Godovikov, I.A.; Shakirova, J.R.; Tunik, S.P.; Podkorytov, I.S.; Shubina, E.S. Luminescent Complexes of the Trinuclear Silver(I) and Copper(I) Pyrazolates Supported with Bis(diphenylphosphino)methane. Inorg. Chem. 2019, 58, 8645-8656. [CrossRef]

(C) 2020 by the authors. Licensee MDPI, Basel, Switzerland. This article is an open access article distributed under the terms and conditions of the Creative Commons Attribution (CC BY) license (http://creativecommons.org/licenses/by/4.0/). 